\title{
Comparative Effects of DDT, Allethrin, Dieldrin and Aldrin-transdiol on Sense Organs of Xenopus laevis
}

\author{
L. M. A. Akkeryans, J. van den Bercken, and M. Verslujus-Helder \\ Institute of Veterinary Pharmacology and Toxicology, University of Utrecht, \\ Utrecht, The Netherlands
}

Received December 6, 1974; accepted January 17, 1975

\begin{abstract}
The effects of IDDT, allethrin, dieldrin and aldrin-transdiol were studied in two different sense organs of Xenopus laevis; the lateral-line organ and the cutaneous touch receptors. DDT and allethrin produced pronounced repetitive firing in both preparations. Dieldrin and aldrin-transdiol, on the other hand, failed to induce any sign of repetitive activity. Aldrin-transdiol, however, caused a marked increase in the rate of spontaneous firing of the lateral-line organ, later followed by a blockade. The repetitive activity in the cutaneous touch receptors, whether induced by DDT or allethrin, was not distinguishable from repetitive firing of the afferent nerve fibers and showed no marked dependence on temperature. This contrasts sharply with the known negative temperature coefficient of the DDT- or allethrin-induced repetitive artivity in the la.teral-line organ.
\end{abstract}

\section{INTRODUCTION}

Repetitive activity was long since recognized as the most characteristic effect of DDT in the nervous system of not only insects but also vertebrates. Sense organs and sensory fibers in particular are highly sensitive to DDT (1-4). The insecticide allethrin, a synthetic pyrethroid, also induces repetitive activity very similar to that produced by DDT $(5,6)$. It has been reported that dieldrin tco causes repetitive trains of impulses in sensory neurones of the cockroach $(7,8)$. But earlier experiments with dieldrin on Xenopus laevis failed to show any sign of repetitivity in the sensory nervous system (4, and unpublished observations). It has recently been proposed that not dieldrin itself but its metabolite aldrin-transdiol is responsible for neurotoxic action in the cockroach (8). This hypothesis was further substantiated when it was shown that aldrin-transdiol had a profound effect on the motor endplate of the frog and the spinal cord of the toad, while in both cases application of dieldrin to the isolated preparation was without any significant effect (9-11). The purpose of the present investigation is to study in more detail the action of dieldrin and aldrintransdiol on sense organs and to compare their effects with those of DDT and allethrin.

\section{MATERIALS AND METHODS}

The experiments were performed on two different sense organ preparations from the clawed toad, Xenopus laevis.

Lateral-line organ. A piece of skin containing several lateral-line organs was removed from the animal and nervous activity was recorded from a single lateralline organ, a so-called stitch, which is innervated by only two afferent nerve 
fibers. Methods for preparation, stimulation and recording were the same as described previously (6).

Cutaneous touch receptors. A piece of skin together with two or three dorsal cutaneous nerves (rami cutanei dorsi mediales) was removed from the animal and pinned down with its outer surface upwards on the bottom of a small vessel. Mechanical stimulation was supplied by means of a fine glass rod (tip diameter $0.5 \mathrm{~mm}$ ) connected to the conus of a small loudspeaker which was mounted on a micromanipulator. Discrete movements of the glass rod were obtained by applying a square voltage pulse of $3-5 \mathrm{msec}$ in duration to the loudspeaker coil. The position of the tip of the glass rod on the surface of the skin was varied until each stimulus induced a single spike in one of the fibers of the dorsal cutaneous nerve.

Recording. Nervous activity was recorded by means of a silver wire electrode. Nerve spikes were amplified with an AC-coupled preamplifier, displayed on an oscilloscope and photographed. Spontaneous activity from the lateral-line organ was measured on a counter after conversion of the spikes to standard pulses with the aid of a triggered pulse generator built specially for this purpose. This instrument also allowed discrimination between the two types of nerve spikes.

Solutions and chemicals. The Ringer's solution used contained (in $\mathrm{m} M$ ) : $\mathrm{NaCl}$ 115, $\mathrm{KCl} 2.5, \mathrm{Na}_{2} \mathrm{HPO}_{4}$ 2.15, $\mathrm{NaH}_{2} \mathrm{PO}_{4}$ $0.85, \mathrm{CaCl}_{2} 2.0 ; \mathrm{pH}$ was adjusted to 7.2 . DDT (purified $p, p^{\prime}$-DDT), allethrin (K and $\mathrm{K}$ Laboratories, Inc.), dieldrin (99.4\% HEOD) and aldrin-transdiol ( $>99 \%$ trans6,7-dihydroxy-dihydro-aldrin) were dissolved in ethanol to make up stock solutions. Small amounts of these solutions were added to the bathing fluid with the aid of a hypodermic syringe with needle No. 27. The final concentration of ethanol, which was less than $0.25 \%$, was found to have no effect in control experiments. Continuous perfusion was not performed to avoid mechanical stimulation of the preparation. Additional experiments were carried out with preparations isolated from animals showing severe symptoms of poisoning after the insecticides had been added to the water in which the animals were kept.

Experiments were carried out at a room temperature of $19-21^{\circ} \mathrm{C}$. When the effect of cooling had to be studied, the solution bathing the preparation was replaced by a solution with a temperature of $10^{\circ} \mathrm{C}$. The temperature in the bath was recorded with a thermistor-thermometer.

\section{RESULTS}

Lateral-line organ. Preparations isolated from animals which had been exposed to $2-5 \mathrm{ppm}$ DDT for about $18 \mathrm{~h}$ or $1-3 \mathrm{ppm}$ allethrin for 20-40 min showed a marked repetitive activity ( $1 \mathrm{ppm}$ is equivalent to $2.8 \times 10^{-6}$ or $3.3 \times 10^{-6} M$ respectively). Single nerve spikes no longer occurred and only trains of repetitive spikes were recorded. In the case of allethrin repetitive activity could also be induced by application of this compound to the outer surface of the skin in the isolated preparation. Figure 1 shows an example of the spontaneous activity from a single lateral-line organ before and after treatment with allethrin.

A clear demonstration has been given that both DDT and allethrin show a definite negative temperature coefficient of activity in this sense organ. Lowering the temperature caused a marked increase in the number of repetitive spikes per train, whereas raising it resulted in a decrease. Besides, evidence has been produced that the repetitive activity in the lateral-line organ does not originate in the afferent nerve fibers, but requires an intact sense organ. Full accounts on the effects of DDT and allethrin on the lateralline organ have been published $(3,6)$.

Treatment of the isolated preparation with dieldrin in concentrations of up to $5 \times 10^{-4} M$ for several hours did not have any significant effect. Similarly, prepara- 

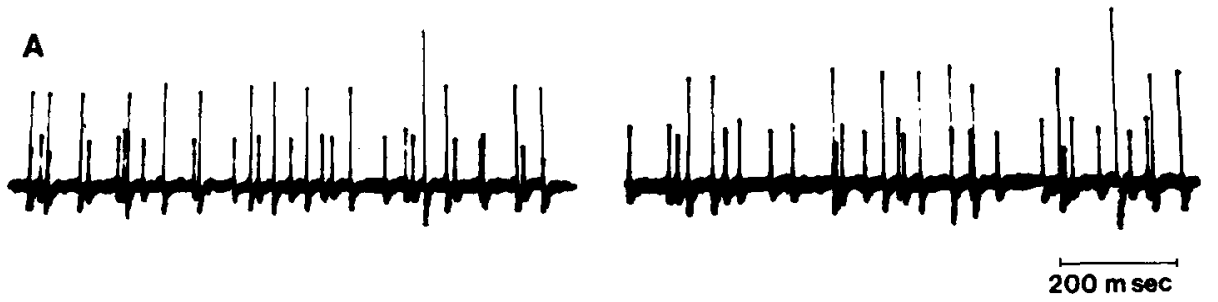

B
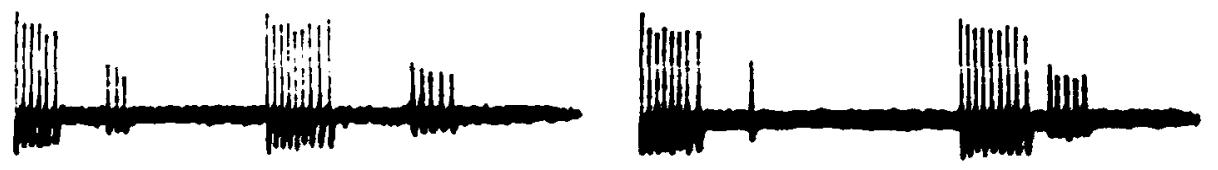

FIG. 1. Spontaneous activity from a single lateral-line organ before (A) and 60 min after exposure to $10^{-5} \mathrm{M}$ allethrin $(B)$.

tions taken from animals showing severe symptoms of poisoning after exposure to 3-5 ppm dieldrin did not show any sign of repetitivity $(1 \mathrm{ppm}$ is equivalent to $2.9 \times 10^{-6} M$ ). Application of aldrintransdiol to the isolated preparation also failed to induce repetitive activity. On the other hand, this metabolite had a marked effect on the rate of spontaneous firing, as illustrated in Fig. 2. Lower concentraticns of aldrin-transdiol caused a distinct increase in the rate of firing at first, followed by a progressive decline and ultimately a complete blockade of spontaneous activity.

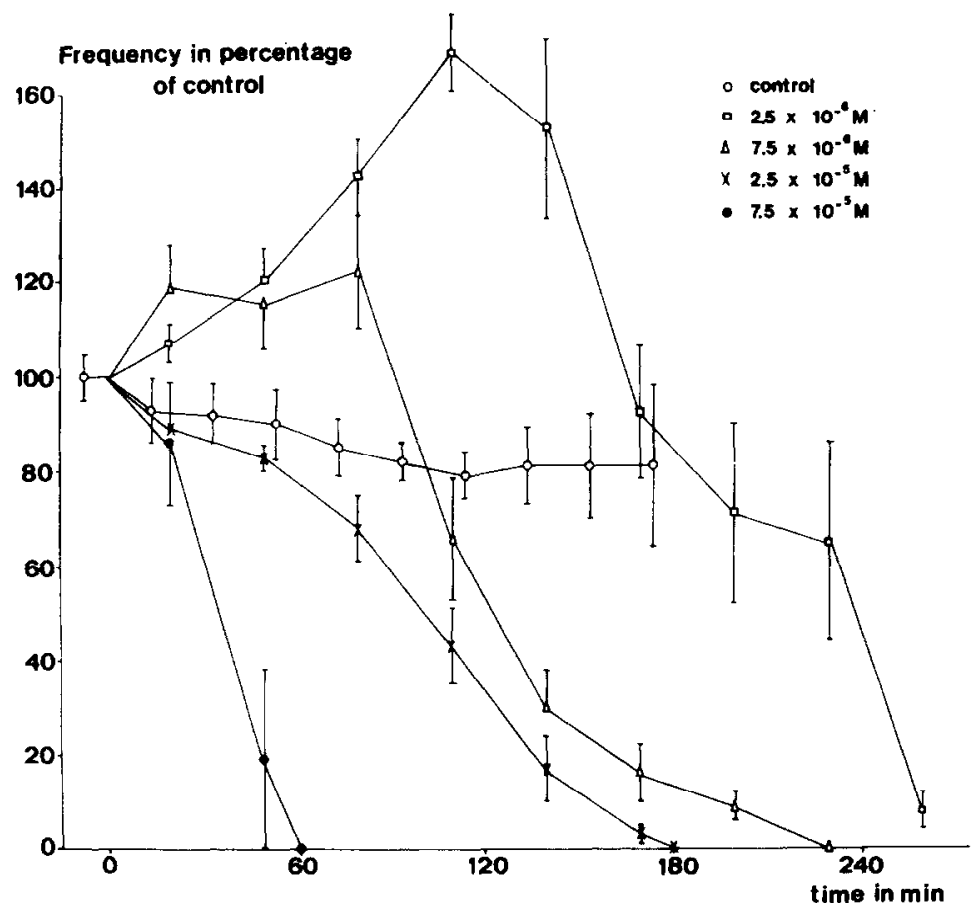

FIG. 2. EDect of aldrin-transdiol on the rate of spontancous firing in single afferent lateral-line nerve fibers. Each point represents the mean frequency $\pm S D$ measured over 18 successive periods of $100 \mathrm{sec}$. 
Higher concentrations produced no initial increase in the rate of discharge and the blockade of spontaneous activity developed much faster. The relation between concentration of aldrin-transdiol and the time required to produce $50 \%$ blockade of the spontaneous activity is plotted in Fig. 3. After all spontaneous activity had disappeared the lateral-line organ was still mechanically sensitive and spikes of full amplitude could be elicited by local water movements, indicating thereby that the blockade of spontaneous firing was not due to impairment of nervous conduction. After prolonged exposure to aldrin-transdiol the evoked responses of the lateral-line organ were also abolished.

Cutaneous touch receptors. Treatment with dieldrin, either in vivo or in vitro, did not cause any sign of repetitive activity in the cutaneous touch receptors. Exposure of the preparation to aldrin-transdiol $\left(10^{-5} \mathrm{M}\right)$ also failed to induce repetitive nerve spikes in response to a brief mechanical stimulus. Since this preparation is not spontancously active, however, a possible blocking effect of aldrin-transdiol cannot be ruled out.

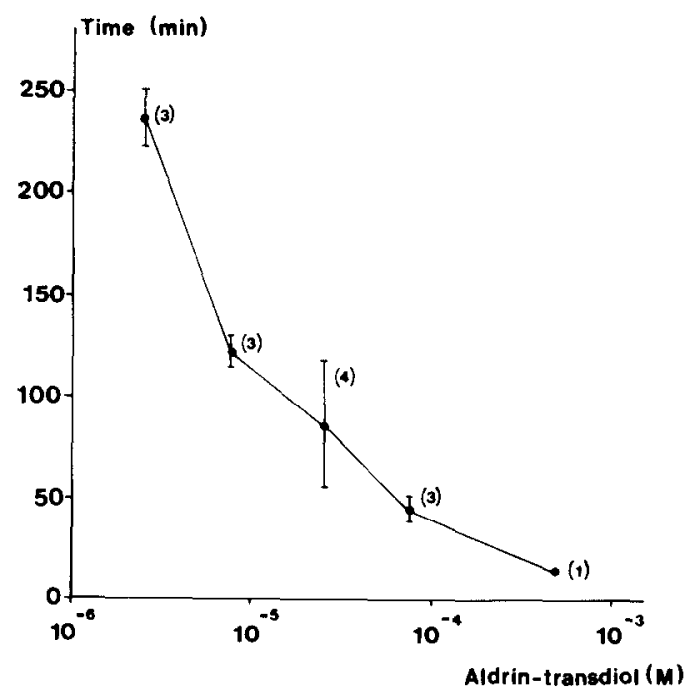

FIG. 3. Relation between concentration of aldrintransdiol and time required to produce a $50 \%$ blockade of the spontaneous activity in the lateral-line organ. Figures indicate number of experiments.
A

$\overline{10 \mathrm{msec}}$

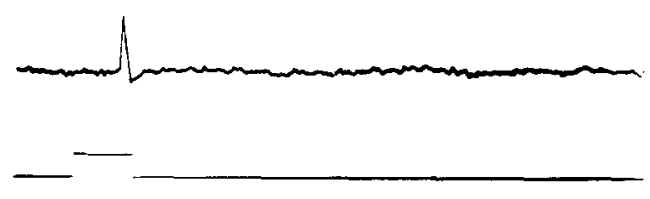

B

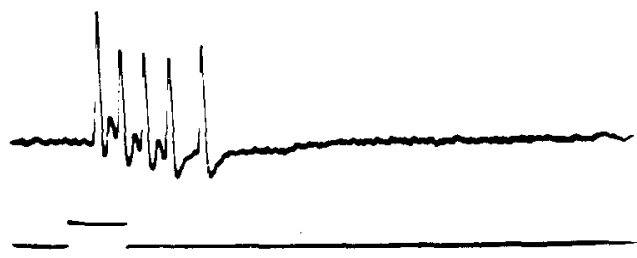

Fig. 4. Response of a cutaneous touch receptor to a brief mechanical stimulus (lower trace) before $(A)$ and after $80 \mathrm{~min}$ of exposure to $10^{-5} \mathrm{M} D D T(B)$.

Preparations from DDT-treated animals invariably showed short trains of spikes in response to a single mechanical stimulus. Such repetitive activity could also be induced by treatment of the isolated preparation with $10^{-5} M$ DDT for $30-90$ min, as illustrated in Fig. 4. The number of repetitive spikes gradually increased with time to a maximum of $8-10$ spikes after 120-180 min of exposure.

Allethrin was more effective than DDT in producing repetitive activity in the isolated preparation. Short trains of spikes were observed as early as 5 min after exposure to $10^{-5} M$ or $15 \mathrm{~min}$ to $10^{-6} M$ allethrin. $\Lambda$ fter longer exposure the number or repetitive spikes was usually much higher than with DDT (Fig. 5B) and in some cases trains of more than 25 spikes were observed (Fig. 5C).

Effects of temperature. A slight increase in the number of repetitive spikes per train induced either by DDT or allethrin in the touch receptors was observed only in a few cases, when the temperature of the preparation was lowered to $10-15^{\circ} \mathrm{C}$. In other cases there was no effect or even a decrease in the number of repetitive spikes after cooling. This contrasts sharply with the lateral- 
line organ where a definite negative temperature coefficient of repetitive activity could be demonstrated $(3,6)$. The situation in the cutaneous touch receptors thus resembles the repetitive firing in isolated nerves of Xenopus, which is also fairly independent of temperature $(3,6)$. This may indicate that the repetitive activity in the cutaneous touch receptors is due to repetitive firing of the afferent nerve fibers. This possibility was tested by stimulating the dorsal cutaneous nerve electrically at the point where it is attached to the skin. In all cases the compound action potential elicited in this way showed almost the same amount of repetitive activity as was obscrved after mechanical stimulation of the skin and no difference could be observed between either repetitive activity.

No significant effects of changes in temperature were noticed in dieldrin- or aldrin-transdiol-treated preparations.

\section{DISCUSSION}

The present experiments definitely demonstrate that, in contrast to DDT and allethrin, the insecticide dieldrin does not produce any repetitive activity either in the lateral-line organ, or in the cutaneous touch receptors of Xenopus laevis. Further, aldrin-transdiol, which is looked upon as one of the active neurotoxic forms of dieldrin, also failed to induce any repetitive activity in both sense organs. These results are at variance with observations in the cockroach where both dieldrin- and aldrintransdiol have been reported to cause repetitive sensory discharges in the metathoracic leg, although less intense than those induced by DDT $(7,8)$. In the present study, however, low concentrations of aldrin-transdiol were found to cause a marked increase in the rate of spontaneous firing of the lateral-line organ. Possibly then a similar increase in spontaneous activity in the sensory neurones of the cockroach appears as trains of impulses.

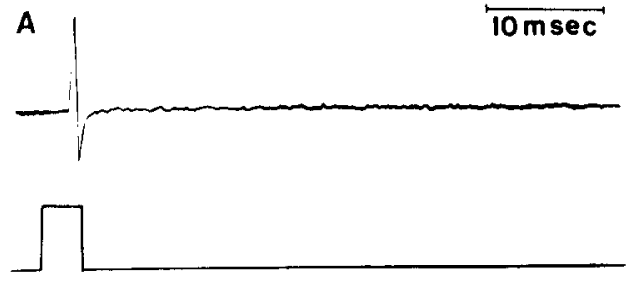

$\mathbf{B}$

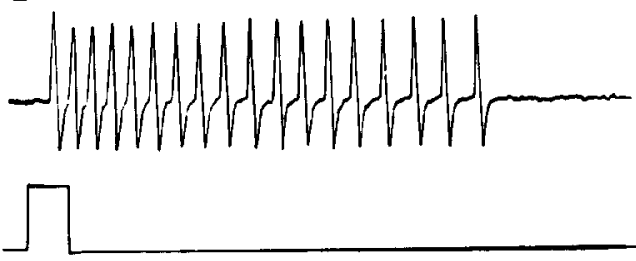

C
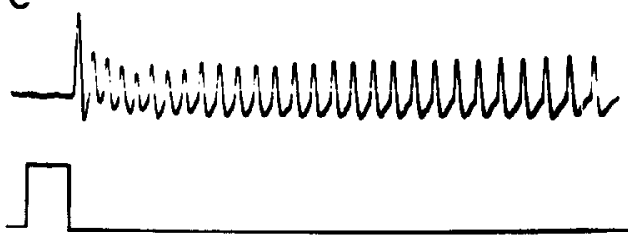

FIG. 5. Response of a cutaneous touch receptor to a brief mechanical stimulus (lower trace) before $(A)$, 30 min after $(B)$ and 60 min after $(C)$ treatment with $10^{-5} \mathrm{M}$ allethrin.

In addition Wang et al. (8) found that aldrin-transdiol also caused a blockade of spontaneous sensory discharges in the cockroach. Such a blocking effect of aldrintransdiol was observed here in the lateralline organ. This latter effect is probably not due to a suppression of nervous conduction by aldrin-transdiol as has been reportcd for the squid giant axon (12), for after complete blockade of the spontaneous activity it was still possible to elicit spikes of full amplitude by mechanical stimulation.

It is conceivable that the site of action of aldrin-transdiol in the lateral-line organ is located at the synapse between the hair cell and the afferent nerve terminal. This possibility is attractive because we have demonstrated that aldrin-transdiol has a marked effect on synaptic transmission in the motor endplate of the frog, causing first a potentiation of both spontaneous 
and evoked transmitter release, later followed by a blockade $(9,10)$. Similar effects of dieldrin or some metabolite on synaptic function have also been observed in the sixth abdominal ganglion of the American cockroach (13). Since in both these systems the transmitter is acetylcholine, it could be that dieldrin and/or aldrin-transdiol affects exclusively cholinergic transmission, as was actually suggested by Shankland and Schroeder (13). However, acetylcholine can probably be excluded as the transmitter at the afferent synapse in the lateral-line hair cells, and recently GABA has been proposed as the excitatory transmitter $(14,15)$. Further, we have observed that application of dieldrin in vivo and aldrin-transdiol in vitro has a profound effect on reflex activity of the amphibian spinal cord, which is difficult to explain on the assumption of a specific effect on cholinergic transmission (11). Thus it seems premature to conclude that the action of dieldrin and aldrin-transdiol is confined to cholinergic junctions only.

The present study demonstrates once more that DDT and allethrin induce repetitive activity in sense organs; allethrin being more effective than DDT. The mechanism underlying the repetitive activity in the lateral-line organ differs probably from that in the cutaneous touch receptors. In the former case repetitive activity occurred in the absence of repetitive firing in the afferent nerve fibers (6), whereas in the latter case the repetitive response elicited by mechanical stimulation could not be distinguished from the repetitive firing evoked by electrical stimulation of the afferent nerve fibers. This difference in mechanism may also explain the absence of an effect of temperature on the repetitive activity in the touch receptors.

Finally, the inability of dieldrin to induce any significant effect in the present experiments as compared with the marked effects of aldrin-transdiol on the lateral-line organ provides a further argument for considering this metabolite as one of the active forms of dieldrin.

\section{ACKNOWLEDGMENTS}

We thank Prof. I)r. H. van Genderen for his interest in this study and Mr. J. M. van der Zalm for construction and maintenance of electronic equipment. We are indebted to Dr. K. W. Jager from Shell International Research Company for the gift of dieldrin and aldrin-transdiol. This work was supported by the Foundation for Medical Research FINGO and by the Shell Corporation.

\section{REFERENCES}

1. K. D. Roeder and E. A. Weiant, The effect of DDT on sensory and motor structures in the cockroach leg, J. Cell. Comp. Physiol. 32, 175 (1948).

2. T. Narashi, Effects of insecticides on excitable tissues, in "Advances in Insect Physiology," (J. W. L. Beament, J. F. Treherne, and V. B. Wigglesworth, Eds.), Vol. 8, p. 1, Academic Press, London and New York, 1971.

3. J. van den Bercken and L. M. A. Akkermans, Negative temperature coefficient of the action of DDT in a sense organ, Eur. J. Pharmacol. 16, 241 (1971).

4. J. van den Bercken, The effect of 1)IT and dieldrin on myelinated nerve fibres, Eur. $J$. Pharmacol. 20, 205 (1972).

5. T. Narahashi, Mode of action of pyrethroids, Bull. Wld. Hlth. Org. 44, 337 (1971).

0. J. van den Bercken, L. M. A. Akkermans, and J. M. van der Zalm, DDT-like action of allethrin in the sensory nervous system of Xenopus lacvis, Eur. J. Pharmacol. 21, 95 (1973).

7. I). Lalonde and A. W. A. Brown, The effert of insecticides on the action potentials of insect nerve, Canad. J. Zool. 32, 74 (1954).

8. C. M. Wang, T. Narahashi, and M. Yamada, The neurotoxic action of dieldrin and its derivatives in the cockroach, Pestir. Biochem. Physiol. 1, 84 (1971).

9. L. M. A. Akkermans, J. van den Bercken, J. M. van der Zalın, and $H$. W. M. van Straaten, Effects of dieldrin (HEOD) and some of its metabolites on synaptic transmission in the frog motor end-plate, Pestic. Biochem. Physiol. 4, 313 (1974).

10. L. M. A. Akkermans, J. van den Bercken, and J. M. van der Zalm, Effects of aldrintransdiol on neuromuscular facilitation and depression, Eur. J. Pharmacol. 31, 166 (1975). 
11. L. M. A. Akkermans, J. van den Bereken, and $M$, Versluijs-Helder, Excitatory and depressant effects of dieldrin and aldrintransdiol in the spinal cord of the toad (Xenopus laevis), Eur. $J$. Pharmacol., in press.

12. J. van den Bercken and T. Narahashi, Effects of aldrin-transdiol - a metabolite of the insecticide dieldrin-on nerve membrane, Eur. J. Pharmacol. 27, 255 (1974).

13. D. L. Shankland and M. E. Schroeder, Phar- macological evidence for a discrete neurotoxic action of dieldrin (HEOD) in the American cockroach, Periplaneta americana (L.), Pestic. Biochem. Physiol. 3, 77 (1973).

14. T. J. Russell, The pharmacology of efferent synapses in the lateral-line system of Xenopus laevis, J. Exp. Biol. 54, 613 (1971).

15. A. Flock and 1). M. K. Lam, Neurotransmitter synthesis in inner ear and lateral line sense organs, Nature (London) 249, 142 (1974). 